\title{
Characterization of Nanoscopic $\mathrm{Cu} /$ Diamond Interfaces Prepared by
} Surface-Activated Bonding: Implications for Thermal Management

Jianbo Liang, Yutaka Ohno, Yuichiro Yamashita, Yasuo Shimizu, Shinji Kanda, Naoto Kamiuchi, Seongwoo Kim, Koyama Koji, Yasuyoshi Nagai, Makoto Kasu, Naoteru Shigekawa

\begin{tabular}{|c|l|}
\hline Citation & ACS Applied Nano Materials. 3(3); 2455-2462 \\
\hline Issue Date & $2020-02-25$ \\
\hline Type & Journal article \\
\hline Textversion & Author \\
\hline Rights & $\begin{array}{l}\text { This document is the Accepted Manuscript version of a Published Work that appeared } \\
\text { in final form in ACS Applied Nano Materials, copyright C American Chemical Society } \\
\text { after peer review and technical editing by the publisher. To access the final edited and } \\
\text { published work see https://doi.org/10.1021/acsanm.9b02558. }\end{array}$ \\
\hline DOI & \begin{tabular}{l}
$10.1021 / a c s a n m .9 b 02558$ \\
\hline
\end{tabular} \\
\hline
\end{tabular}

Self-Archiving by Author(s)

Placed on: Osaka City University

LIANG, J., et al. (2020). Characterization of Nanoscopic Cu/Diamond Interfaces Prepared by Surface-Activated Bonding: Implications for Thermal Management. ACS Applied Nano Materials. 3, 2455-2462. Doi:10.1021/acsanm.9b02558 


\section{Characterization of Nanoscopic Diamond/Cu Interface Prepared by Surface Activated Bonding: Implications for Thermal Management}

Jianbo Liang ${ }^{*}, 1$, Yutaka Ohno ${ }^{2}$, Yuichiro Yamashita ${ }^{3}$, Yasuo Shimizu ${ }^{4}$, Shinji Kanda ${ }^{1}$, Naoto Kamiuchi ${ }^{5}$, Seongwoo Kim ${ }^{6}$, Koyama Koji ${ }^{6}$, Yasuyoshi Nagai ${ }^{4}$, Makoto Kasu ${ }^{7}$, and Naoteru Shigekawa ${ }^{1}$

${ }^{1}$ Department of Electronic Information Systems, Osaka City University, 3-3-138 Sumiyoshi, Osaka 558-8585, Japan

${ }^{2}$ Institute for Materials Research (IMR), Tohoku University, 2-1-1 Katahira, Sendai 980-8577, Japan

${ }^{3}$ National Metrology Institute of Japan, National Institute of Advanced Industrial Science and Technology, Tsukuba, Ibaraki 305-8563, Japan

${ }^{4}$ Institute for Materials Research (IMR), Tohoku University, 2145-2 Narita, Oarai, Ibaraki 311-1313, Japan

${ }^{5}$ The Institute of Scientific and Industrial Research (ISIR), Osaka University, 8-1 Mihogaoka, Osaka 567-0047, Japan

${ }^{6}$ Adamant Namiki Precision Jewel. Co., Ltd, Shinden 3-8-22 Adachi-ku, Tokyo 123-8511, Japan

${ }^{7}$ Department of Electrical and Electronic Engineering, Saga University, 1 Honjo-machi, Saga 8408502, Japan

ABSTRACT: The microstructures of $\mathrm{Cu}$ /diamond interfaces prepared by surface-activated bonding at room temperature are examined by cross-sectional scanning transmission electron microscopy (STEM). A crystalline defect layer composed of $\mathrm{Cu}$ and diamond with a thickness of approximately $4.5 \mathrm{~nm}$ is formed at the as-bonded interface, which is introduced by irradiation with an Ar beam during the bonding process. No crystalline defect layer is observed at the $700{ }^{\circ} \mathrm{C}$-annealed interface, which is attributed to the recrystallization of the defect layer due to the high-temperature annealing process. 
Instead of the defect layer, a mating interface layer and a copper oxide layer are formed at the interface.

The mating interface layer and the copper oxide layer play a role in relieving the residual stress caused by the different thermal expansion coefficients of diamond and $\mathrm{Cu}$. The thermal boundary resistance (TBR) of the as-bonded interface is measured to be $1.7 \pm 0.2 \times 10^{-8} \mathrm{~m}^{2} \mathrm{~K} / \mathrm{W}$ by the time domain pulsedlight-heating thermoreflectance technique, and this value is virtually the same as the theoretical calculation value. These results indicate that the direct bonding of diamond and $\mathrm{Cu}$ is a very effective technique for improving the heat-dissipation performance of power devices.

KEYWORDS: $\mathrm{Cu} /$ diamond direct bonding, thermal boundary resistance, interfacial microstructure, thermal conductivity

\section{INTRODUCTION}

Due to the ultra-miniaturization, high integration, and high performance of semiconductor devices, a large amount of heat will be generated during their operation. This heat has become an important problem restricting the development of the microelectronics industry because it will significantly degrade the device's performance and reliability. To solve the dispersion problem, various highthermal conductivity materials, such as $\mathrm{SiC},{ }^{1} \mathrm{AlN},{ }^{2}$ carbon fibers, ${ }^{3}$ and graphene/Cu composites, ${ }^{4,5}$ have been developed. Diamond has the highest thermal conductivity of $22 \mathrm{~W} / \mathrm{cm} \cdot \mathrm{K}$ and is the most ideal material for suppressing the rise in device temperature during operation. ${ }^{6,7}$

AlGaN/GaN high-electron-mobility transistors (HEMTs) on diamond have realized a large 
improvement in thermal management and an increase in device output power levels. ${ }^{8-10}$ In actual operation, AlGaN/GaN HEMTs on diamond would be directly mounted onto a heat sink by solder bonding in a device module. ${ }^{11-13}$ The thermal conductivity of the $\mathrm{AgSn}(0.33 \mathrm{~W} / \mathrm{cm} \cdot \mathrm{K})$ and $\mathrm{AuSn}(0.57$ $\mathrm{W} / \mathrm{cm} \cdot \mathrm{K})$ used for solder bonding is lower than that of the heat sink materials $\mathrm{Al}(2.36 \mathrm{~W} / \mathrm{cm} \cdot \mathrm{K})$ and $\mathrm{Cu}(3.98 \mathrm{~W} / \mathrm{cm} \cdot \mathrm{K})$. Therefore, a large thermal resistance would be generated between the diamond and the heat sink, which would have a strong, unfavorable impact on the thermal dissipation of devices. ${ }^{14,15}$ The mounting interface cannot fulfill the requirement of the transferring capability of heat generated in $\mathrm{AlGaN} / \mathrm{GaN}$ HEMTs on the diamond.

Wafer bonding is an important technique for the fabrication of three-dimensional large-scale integrated circuits, ${ }^{16}$ optical electrical integrated circuits, ${ }^{17}$ and micro-electromechanical system packaging. ${ }^{18}$ Among all the bonding methods, surface activated bonding (SAB) is the only way to directly bond materials with large differences in thermal expansion coefficients and lattice constants at room temperature by mating surfaces activated by fast atom beams of Ar prior to bonding in a high vacuum. ${ }^{19-21}$ The direct bonding of diamond and $\mathrm{Al}$ or $\mathrm{Cu}$ would be a promising technique for improving the thermal boundary resistance (TBR) of the mounting interface. It has been reported that the TBR of an Si interface fabricated by $\mathrm{SAB}$ is equivalent to the thermal resistance of micrometerthick bulk Si. ${ }^{22}$ Furthermore, the TBR could be greatly improved by the annealing process due to the recrystallization of the amorphous layer formed at the interface. We have previously reported the direct bonding of diamond and $\mathrm{Al}$, and $\mathrm{Cu}$ at room temperature by surface activated bonding $(\mathrm{SAB})$ and 
demonstrated the thermal stability of their bonding interfaces ${ }^{23,24}$ However, the effect of the annealing temperature on the atomic diffusion of the $\mathrm{Cu}$ /diamond interface, the thermal stability mechanism and the thermal conductivity of the interface are still unknown, and these are crucially important characteristics for better understanding the physical properties of the bonding interface and the application of the bonding interface for the heat dissipation of devices.

In this work, we investigate the atomic behavior of the $\mathrm{Cu}$ /diamond bonding interface annealed at various temperatures by scanning transmission electron microscopy (STEM) and energy-dispersive Xray spectroscopy (EDX) and the thermal stability mechanism of the bonding interface. The thermal properties of the $\mathrm{Cu}$ /diamond interface are evaluated by the time domain pulsed-light-heating thermoreflectance technique.

\section{EXPERIMENTAL DETAILS}

The direct bonding of diamond and $\mathrm{Cu}$ was achieved at room temperature by SAB technology. We used a single-crystal diamond (100) substrate synthesized by the high-pressure and high-temperature (HPHT) method and a commercial $\mathrm{Cu}$ plate made by the roller method. The sizes of diamond and $\mathrm{Cu}$ were $4 \mathrm{~mm} \times 4 \mathrm{~mm} \times 0.5 \mathrm{~mm}$ and $10 \mathrm{~mm} \times 10 \mathrm{~mm} \times 0.25 \mathrm{~mm}$, respectively. The surfaces of the diamond and $\mathrm{Cu}$ were cleaned with acetone and isopropyl alcohol in an ultrasonic bath for $300 \mathrm{~s}$, dried under an $\mathrm{N}_{2}$ flow, and then set in the SAB facility for direct bonding. Before bonding, the surfaces of the diamond and $\mathrm{Cu}$ were simultaneously irradiated by Ar fast atom beams (FAB) with a current of 1.7 
$\mathrm{mA}$ at an applied voltage of $1.7 \mathrm{kV}$ for $180 \mathrm{~s}$ in a high vacuum of $5 \times 10^{-6} \mathrm{~Pa}$. After surface irradiation, the diamond and $\mathrm{Cu}$ were immediately brought into contact by applying a pressure of $10 \mathrm{MPa}$ at room temperature for $60 \mathrm{~s}$ so that $\mathrm{Cu} /$ diamond direct bonding was fabricated by SAB. The microstructural and STEM-EDS analyses of the $\mathrm{Cu}$ /diamond interfaces were performed with a JEOL JEM-ARM200F analytical microscope. The samples for STEM observation were fabricated using a focused ion beam (FIB) technique (Thermo Fisher Scientific: Helios NanoLab600i). The effect of the annealing temperature on the microstructure of the interface was also investigated. The annealing process was conducted at 500 and $700{ }^{\circ} \mathrm{C}$ with a heating rate of $50{ }^{\circ} \mathrm{C} / \mathrm{min}$ in ambient $\mathrm{N}_{2}$ gas for $5 \mathrm{~min}$, and the cooling was not controlled.

The TBR of the $\mathrm{Cu}$ /diamond bonding interface was measured by the time domain pulsed-lightheating thermoreflectance technique. ${ }^{25} \mathrm{~A}$ thin-Cu/diamond bonding structure was fabricated to investigate the TBR of the bonding interface. First, a thin $\mathrm{Cu}$ film was deposited onto the photoresist layer coating the Si substrate by electron beam evaporation (EBE). The evaporation-deposited $\mathrm{Cu}$ film and diamond substrate were bonded by SAB, and then the Si substrate was removed by removing the photoresist layer using acetone. Finally, a thin Mo film was evaporated onto the $\mathrm{Cu}$ bonded to diamond by EBE, as shown in Figure 1. The thicknesses of the $\mathrm{Cu}$ and Mo thin film were measured to be 100 and $84 \mathrm{~nm}$, respectively, by a Stylus Profiler (Alpha-Step D-500) with a high resolution of $0.038 \mathrm{~nm}$. In addition, $\mathrm{Cu}$ and $\mathrm{Mo}$ thin films with the same thickness were evaporated separately onto a diamond substrate and were used as references. 
The measurement system consisted of a pump laser and a probe laser, as shown in Figure 1. The repetition rate, wavelength, optical power, and spot radius of the pump laser were $20 \mathrm{MHz}, 1550 \mathrm{~nm}$, $30 \mathrm{~mW}$, and $70 \mu \mathrm{m}$, respectively. The same parameters of the probe laser were $20 \mathrm{MHz}, 775 \mathrm{~nm}, 1.5$ $\mathrm{mW}$, and $15 \mu \mathrm{m}$, respectively. A Mo film was employed as a transducer film. The pump laser with an intensity modulation of $200 \mathrm{kHz}$ was used to irradiate the Mo film surface. The probe laser beam was focused on the same irradiation spot, with a specific time delay controlled by an arbitrary function generator. The reflected probe laser beam was detected by a photodetector. The transient temperature of the heated area was detected as the phase signal of a lock-in amplifier. ${ }^{26}$ The signal was recorded as a function of the delay time of the probe laser pulse relative to the pump laser pulse, which was $10 \mathrm{~ns}$. The transient temperature curve depends on the thermophysical properties of the layers and the TBR between layers through which the heat flow passe. Here, $d$ is the film thickness, $C$ is the volumetric heat capacity, $\kappa$ is the thermal diffusivity, $\alpha$ is the absorption coefficient, $b$ is the thermal effusivity, and $R$ is the TBR. Since the diameters of the laser spots are more than 100 times larger than the film thickness, one-dimensional heat conduction can be assumed during data analysis using a lock-in signal simulation for the thermal reflectance measurement. ${ }^{27}$

\section{RESULTS AND DISCUSSION}

The three-dimensional AFM images and the corresponding cross-sectional profiles of the $\mathrm{Cu}$ plate, the deposited $\mathrm{Cu}$ thin film, and the diamond substrate surfaces are shown in Figures 2(a) and 2(b), 2(c) 
and 2(d), and 2(e) and 2(f), respectively. The averaged roughness (Ra) values of the $\mathrm{Cu}$, the deposited $\mathrm{Cu}$ thin film, and the diamond substrate surface were determined to be $2.4,1.9$ and $0.4 \mathrm{~nm}$, respectively. The differences between the peaks and valleys of the $\mathrm{Cu}$ plate, the deposited $\mathrm{Cu}$ thin film, and the diamond substrate surface were determined to be approximately $8.5,10.8$ and $2.2 \mathrm{~nm}$, respectively. The $\mathrm{Cu}$ plate used in the experiment was manufactured by the roller rolling method, so the surface roughness was rather high. In addition, the surface of the deposited $\mathrm{Cu}$ thin film was also very rough, and the main reason for this effect could be attributed to the rough surface of the photoresist layer coating the Si. The diamond surface had been polished, so its surface was extremely flat. The surface roughness of bonding materials is a critical factor in wafer direct bonding at room temperature. Bonding materials with nano-level flatness will largely produce a lower formation of voids, which efficiently increases the bonding strength. Although the $\mathrm{Cu}$ surface was rougher, it easily deformed when a large pressure was applied. Therefore, although the $\mathrm{Cu}$ plate and the deposited $\mathrm{Cu}$ thin film had large Ra values describing the surface roughness, it was still possible to bond both directly to diamond.

Figures 3(a), 3(b), and 3(c) show cross-sectional STEM images of the as-bonded Cu/diamond interface and the interfaces annealed at 500 and $700{ }^{\circ} \mathrm{C}$, respectively. The microstructure of the bonding interface was visible. No structural defects or nanovoids were observed at the interfaces even after annealing at the high temperature of $700{ }^{\circ} \mathrm{C}$. A sharp interface and an approximately $4.5 \mathrm{~nm}$-thick intermediate layer were observed at the as-bonded $\mathrm{Cu} /$ diamond interface [Figure 3(a)]. Some lattice 
fringes of $\mathrm{Cu}$ and diamond arranged coherently across the interface were observed. This result indicates that the intermediate layer was composed of a crystal defect layer of $\mathrm{Cu}$ and diamond. The thicknesses of the crystal defect layers of $\mathrm{Cu}$ and diamond were measured to be approximately 1.5 and $3 \mathrm{~nm}$, respectively. After annealing at $500{ }^{\circ} \mathrm{C}$, no Cu crystal defect layer was observed, and the thickness of the diamond crystal defect layer decreased to approximately $2 \mathrm{~nm}$. Furthermore, when the annealing temperature was increased to $700{ }^{\circ} \mathrm{C}$, no diamond crystal defect layer was observed at the interface. Instead of the crystal defect layer, a mating layer composed of $\mathrm{Cu}$ and diamond with a thickness of approximately $3 \mathrm{~nm}$ was observed at the interface [Figure 3(c)]. The thickness of the defect layer and the mating layer was nonuniform, which should have been related to the roughness values of the $\mathrm{Cu}$ and diamond surfaces.

The $\mathrm{X}$-ray intensity profiles of the $\mathrm{C}, \mathrm{Cu}, \mathrm{O}, \mathrm{Ar}, \mathrm{Ti}$, and $\mathrm{Fe}$ atoms across the as-bonded $\mathrm{Cu} /$ diamond interface and the interface annealed at 500 and $700{ }^{\circ} \mathrm{C}$ are shown in Figures 4(a), 4(b), and 4(c), respectively. The red dotted line shows the averaged intensity of the background noise. For the $\mathrm{O}$, Ar, $\mathrm{T}$, and $\mathrm{Fe}$ atoms, the X-ray intensity near the interface was clearly higher than that at the position separated from the interface, which indicates that the $\mathrm{O}, \mathrm{Ar}, \mathrm{T}$, and $\mathrm{Fe}$ atoms were distributed in the interface. $\mathrm{O}$ and Ar atoms were detected at the as-bonded interface, and were at the background level. Small signal peaks from Ti and Fe atoms were observed at the as-bonded interface, which could have been due to contaminants that formed from the metal vacuum chamber during the activation process. After annealing at $500{ }^{\circ} \mathrm{C}$, the signal peak of Ti atoms was still observed at the interface. In addition, 
a small signal peak of $\mathrm{O}$ atoms was also observed at the interface. However, no signal peak of Fe atom was observed at the interface. This observation could have been because the concentration of Fe atom distributed at the interface was below the resolution of the detector sensor due to diffusion after annealing. When the annealing temperature increased to $700{ }^{\circ} \mathrm{C}$, the signal peak intensity of $\mathrm{O}$ atoms became stronger [Figure 4(c)]. However, no a change was observed in the peak intensity of Ti atoms. The enhancement of the $\mathrm{O}$ atom peak intensity could be attributed to the increase in the concentration of $\mathrm{O}$ atoms distributed near the interface after annealing. This result indicated that an oxide layer was formed at the $700{ }^{\circ} \mathrm{C}$-annealed interfaces. For the Ar atoms, no signal peak was observed at the asbonded interface or at the interfaces annealed at 500 and $700{ }^{\circ} \mathrm{C}$, which indicated that the concentration of Ar atoms distributed at the interface was exceptionally low.

Figures 5(a) shows the thermal reflectance signals (solid lines) of the $\mathrm{Cu} /$ diamond interfaces fabricated by the SAB and EBE methods. Fittings of the thermoreflectance signals were performed within the range of $0.5-10$ ns using a simulated lock-in thermoreflectance signal (solid circle) to obtain the TBR between the $\mathrm{Cu}$ and diamond. The parameters used in the fittings are shown in Table I. The thermal diffusivity and the thermal conductivity of the Mo thin film were determined to be 2.1 $\times 10^{-6} \mathrm{~m}^{2} / \mathrm{S}$ and $0.053 \mathrm{~W} / \mathrm{cm} \cdot \mathrm{K}$, respectively, by determining an 99-nm-thick Mo thin film evaporated onto a quartz substrate using the rear heating/front detection-type pulsed-light heating time-domain thermal reflectance technique. ${ }^{28}$ The TBR between $\mathrm{Mo}$ and $\mathrm{Cu}$ was obtained to be approximately 1.4 $\times 10^{-8} \mathrm{~m}^{2} \cdot \mathrm{K} / \mathrm{W}$, which is significantly larger than the previously reported value. ${ }^{29}$ The reason is that 
there were not enough electron carriers. Since the obtained thermal diffusivity value of the Mo thin film is very small, the density of the Mo thin film should also be small. In addition, the surface of $\mathrm{Cu}$ bonded to diamond was exposed to the atmosphere prior to deposition of the Mo film, so an oxide layer could have formed on the $\mathrm{Cu}$ surface, which may have caused thermal resistance. The TBR values of the $\mathrm{Cu} /$ diamond interfaces prepared by $\mathrm{SAB}$ and EBE were determined to be both $1.7 \times 10^{-8} \mathrm{~m}^{2}$. $\underline{\mathrm{K}} / \mathrm{W}$. Furthermore, the obtained TBR values of the $\mathrm{Cu} /$ diamond interface are in good agreement with the value of $1.13 \times 10^{-8} \mathrm{~m}^{2} \cdot \mathrm{K} / \mathrm{W}$ calculated by the phonon diffuse mismatch model. ${ }^{30}$ The absolute values of sensitivity around best fitted value of unknown parameters are shown in Figure 5(b). The difference between sensitivities of TBR of $\mathrm{Cu} /$ diamond and that of TBR of $\mathrm{Mo} / \mathrm{Cu}$ is little. Therefore, both unknown parameters (TBR of $\mathrm{Mo} / \mathrm{Cu}$ and TBR of $\mathrm{Cu} /$ diamond) can be determined. Uncertainties of TBR $\left(u_{T B R}\right)$ for $\mathrm{Mo} / \mathrm{Cu}$ interface and $\mathrm{Cu} /$ diamond are calculated using the law of propagation of uncertainty, that is following equation:

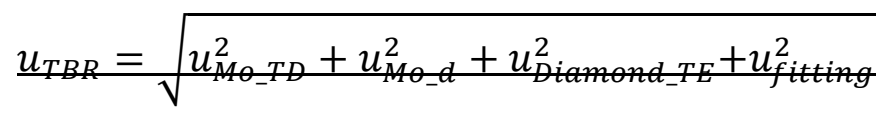

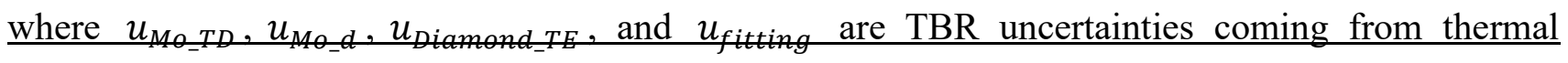
diffusivity of Molybdenum, thickness of Molybdenum, thermal effusivity of Diamond and standard deviation on fitting results when the best fit case, respectively. Consequently, we report TBR values with the expanded uncertainty with conversion factor $(\mathrm{k}=2)$ as shown in the Table II. Uncertainties of $\underline{\mathrm{TBR} \text { for the } \mathrm{Cu} / \text { diamond interfaces prepared by } \mathrm{SAB} \text { and } \mathrm{EBE} \text { were determined to be } \pm 0.2 \times 10^{-8} \text { and }}$ $\pm 0.3 \times 10^{-8} \mathrm{~m}^{2} \cdot \mathrm{K} / \mathrm{W}$, respectively. 
We found that the crystal defect layer formed at the as-bonded $\mathrm{Cu}$ /diamond interface was unlike those in previous reports involving $\mathrm{SAB}$-fabricated $\mathrm{Si} / \mathrm{Si},{ }^{31} \mathrm{Si} / \mathrm{GaAs},{ }^{32}$ and $\mathrm{Si} / \mathrm{SiC}^{33}$ interfaces. It is generally believed that the amorphous layer is formed at the bonding interface due to excessive Ar beam irradiation during the bonding process. However, not all materials irradiated by the Ar beam will become amorphous. It has been reported that a very thin crystal defect layer was induced at the $\mathrm{GaAs} / \mathrm{GaAs}^{34}$ and $\mathrm{Cu} / \mathrm{Cu}^{35}$ homointerfaces fabricated by SAB. An GaAs crystal defect layer and an a$\mathrm{Si}$ amorphous layer were formed at the GaAs and Si sides of the bonding interface, respectively, as reported. ${ }^{34}$ These results indicate that Ar beam-irradiation will induce a partial crystal defect at the $\mathrm{Cu}$ and diamond bonding surfaces.

No oxygen atoms were detected at the as-bonded interface, which is different from the result previously reported for an $\mathrm{Al} /$ diamond interface. ${ }^{23}$ This result could have occurred because no oxide layer was formed at the interface or because the concentration of $\mathrm{O}$ atoms distributed at the interface was too low to detect. The oxidation temperature of copper is higher than $300{ }^{\circ} \mathrm{C}$ under atmospheric ambient conditions. ${ }^{36}$ Therefore, it is difficult for the $\mathrm{Cu}$ surface irradiated by the Ar beam to immediately react with the residual oxygen in the vacuum chamber to form a copper oxide at room temperature. As the annealing temperature increases, the $\mathrm{O}$ atoms distributed at the interface will be concentrated. The concentrated $\mathrm{O}$ atoms will react with $\mathrm{Cu}$ to form copper oxide. The oxide layer observed in the X-ray intensity profile of the $700{ }^{\circ} \mathrm{C}$-annealed interfaces should be this copper oxide layer. 
It is important to note that the difference between the thermal expansion coefficients of $\mathrm{Cu}(16.42 \times$ $\left.10^{-6} / \mathrm{K}\right)$ and diamond $\left(2.3 \times 10^{-6} / \mathrm{K}\right)$ is very large, while no mechanical phenomena, such as cracks or interface separation, were observed at the annealed interface. This result implies that the bonding interface with a high thermal stability could be related to the structural properties of the composite layer formed at the interface. The $\mathrm{Cu}$ and diamond surfaces had nano-level roughness, so nanovoids should have been formed at the bonding interface. However, no nanovoids were observed at the interface. This result could have occurred due to the plastic deformation of the $\mathrm{Cu}$ bonding surface. The $\mathrm{Cu}$ and diamond surfaces made intimate contact to form a nano-level composite interface. The structure of the composite interface was difficult to identify by STEM observation due to the crystal defect layer formed at the interface. After annealing at $700{ }^{\circ} \mathrm{C}$, the crystal defect layer was recovered, so the structure of the composite layer could be recognized. The recovery of the crystal defect layer was very similar to the findings in previous reports, indicating that the damaged layer formed at the interface by Ar beam irradiation can be recrystallized through a high-temperature annealing process. ${ }^{35,37,38}$

The thermal expansion coefficient of the composite layer composed of $\mathrm{Cu}$ and diamond should be different from those of the bulk diamond and $\mathrm{Cu}$. It has been reported that the thermal expansion coefficient of the composite material composed of $\mathrm{Cu}$ and diamond highly depends on the component ratio between diamond and $\mathrm{Cu}$, decreasing with increasing amounts of the diamond component. ${ }^{39}$ The composite layer played a role in relieving the residual stress generated by the difference in the thermal 
expansion coefficients between diamond and $\mathrm{Cu}$. Similar results have been reported for a diamond/Si interface fabricated by $\mathrm{SAB}$, wherein a $\mathrm{SiC}$ intermediate layer was formed at the $1000{ }^{\circ} \mathrm{C}$-annealed interface to play a role in relaxing the residual stress. ${ }^{40}$ In addition, copper oxide is well known to have a low thermal expansion coefficient $\left(\mathrm{Cu}_{2} \mathrm{O}: 1.8 \sim 2.8 \times 10^{-6} / \mathrm{K}\right.$ and $\left.\mathrm{CuO}: 5.9 \times 10^{-6} / \mathrm{K}\right)$ at room temperature. ${ }^{41,42}$ The copper oxide formed at the interface could also play a role in reducing the stress caused by the difference in the thermal expansion coefficient between $\mathrm{Cu}$ and diamond. A similar result has been reported, indicating that copper oxide formed at the defect sites of plasma-treated graphene played an efficient role in enhancing the load transfer and thermal stress relaxation between graphene and $\mathrm{Cu}$ matrixes. ${ }^{43,44}$

The surface of the $\mathrm{Cu}$ thin film bonded to diamond exhibits substantial roughness. The difference between the peaks and valleys on the $\mathrm{Cu}$ thin film surface is about $\pm 15 \mathrm{~nm}$, at best, according to the AFM image (Figure 2(d)). Even if the $\mathrm{Cu}$ film thickness changes from $84 \mathrm{~nm}$ to $114 \mathrm{~nm}$, the thermal resistance of the $\mathrm{Cu}$ thin film is in the order of $10^{-10} \mathrm{~m}^{2} \cdot \mathrm{K} / \mathrm{W}$ and is sufficiently smaller than the interfacial thermal resistance, so the effect of surface roughness can be ignored. For the Mo thin film, since the thermal resistance of the Mo thin film is approximately $1.4 \times 10^{-8} \mathrm{~m}^{2} \cdot \mathrm{K} / \mathrm{W}$, the effect of the Mo thin film roughness is quite large. Importantly, the TBR value of the $\mathrm{Cu} /$ diamond bonded structure is the same as that of the $\mathrm{Cu} /$ diamond evaporated structure. These results suggest that the effect of the crystal defect layer formed at the interface on the phonon transport properties across the bonding interface is small and can be ignored. The $\mathrm{Cu}$ /diamond bonding interface with thermal stability at up 
to $700^{\circ} \mathrm{C}$ is fully competent for use in addressing power-device temperature increases during operation.

All the experimental results indicated that the direct bonding of diamond and $\mathrm{Cu}$ is an excellent technique by which to reduce the thermal resistance between diamond and $\mathrm{Cu}$ due to the absence of solder materials.

\section{CONCLUSIONS}

The microstructures and thermal conductive properties of the $\mathrm{Cu} /$ diamond interfaces prepared by SAB at room temperature were characterized by STEM and the time domain pulsed-light-heating thermoreflectance technique. No mechanical defects, such as cracks or voids, were observed at the interface, even at an annealing a temperature of $700{ }^{\circ} \mathrm{C}$. An approximately $4.5 \mathrm{~nm}$-thick crystal defect layer consisting of diamond and $\mathrm{Cu}$ was formed at the as-bonded interface. The thickness of the crystal defect layer decreased as the annealing temperature increased. Finally, the crystal defect layer was recovered after annealing at $700{ }^{\circ} \mathrm{C}$. A mating interface layer and a copper oxide layer replacing the defect layer were observed at $700{ }^{\circ} \mathrm{C}$-annealed interfaces, which played a role in relieving the residual stresses caused by the different thermal expansion coefficients between diamond and $\mathrm{Cu}$. The TBR value of the $\mathrm{Cu} /$ diamond bonded structure was determined to be $1.7 \pm 0.2 \times 10^{-8} \mathrm{~m}^{2} \cdot \mathrm{K} / \mathrm{W}$, which was consistent with that of the $\mathrm{Cu} /$ diamond evaporated structure. These results indicated that the $\mathrm{Cu} /$ diamond interface prepared by $\mathrm{SAB}$ is highly useful for connecting diamond and heat-sink materials for high-power applications. 


\section{AUTHOR INFORMATION}

Corresponding Author

*E-mail: liang@osaka-cu.ac.jp

\section{ACKNOWLEDGMENTS}

This work was supported by the "Research and development of high thermal stability interface by direct bonding of diamond" project in the Feasibility Study Program of New Energy and Industrial Technology Development Organization (NEDO) (contract number: 19101242-0). The fabrication of the STEM samples and part of the STEM observation were respectively performed at The Oarai Center and at the Laboratory of Alpha-Ray Emitters in IMR under the Inter-University Cooperative Research in IMR of Tohoku University (NO. 18M0045 and 19M0037). STEM-EDS was performed at ISIR under the Cooperative Research Program of "Network Joint Research Center for Materials and Devices: Dynamic Alliance for Open Innovation Bridging Human, Environment and Materials” (No. 20191240). 


\section{REFERENCES}

(1) Chu, K.; Jia, C.; Liang, X.; Chen. H.; Guo, H.; Yin, F. et al., Experimental and modeling study of the thermal conductivity of SiCp/Al composites with bimodal size distribution. J. Mater. Sci. 2009, $44,4370-4378$.

(2) Kida, M.; Weber, L.; Monachon, C.; Mortensen, A. Thermal conductivity and interfacial conductance of AlN particle reinforced metal matrix composites. J. Appl. Phys. 2011, 109, 47-355.

(3) Ullbrand, J. M.; Córdoba, J. M.; Tamayo-Ariztondo, J.; Elizalde, M. R.; Nygren, M. MolinaAldareguia, J. M.; Odén, M. Thermomechanical properties of copper-carbon nanofiber composites prepared by spark plasma sintering and hot pressing. Compos. Sci. Technol. 2010, 70, 2263-2268.

(4) Chu, K.; Wang, X. H.; Wang, F.; Li, Y. B.; Huang, D. J.; Liu, H.; Ma, W. L.; Liu, F. X.; Zhang, H. Largely enhanced thermal conductivity of graphene/copper composites with highly aligned graphene network. Carbon 2018, 127, 102-112.

(5) Chu, K.; Wang, X. H.; Li, Y. B.; Huang, D. J.; Geng, Z. R.; Zhao, X. L.; Liu, H.; Zhang, H. Thermal properties of graphene/metal composites with aligned graphene. Mater. Des. 2018, 140, 85-94.

(6) Yamamoto, Y.; Imai, T.; Tanabe, K.; Tsuno, T.; Kumazawa, Y.; Fujimori, N. The measurement of thermal properties of diamond. Diam. Relat. Mater. 1997, 6, 1057 - 1061.

(7) Nosaeva, K.; Weimann, N.; Rudolph, M.; John, W.; Krueger, O. W. Heinrich, Improved thermal management of InP transistors in transferred-substrate technology with diamond heat-spreading layer. Electron. Lett. 2015, 51, 1010 - 1012. 
(8) Sun, H.; Simon, R. B.; Pomeroy, J. W.; Francis, D.; Faili, F.; Twitchen, D. J.; Kuball, M.; Reducing GaN-on-diamond interfacial thermal resistance for high power transistor applications. Appl. Phys. Lett. 2015, 106, No. 111906.

(9) Francis, D.; Faili, F.; Babic, D.; Ejeckam, Nurmikko, F. A.; Maris, H.; Formation and characterization of 4-inch GaN-on-diamond substrates. Diamond Relat. Mater. 2012, 19, 229 233.

(10) Pomeroy, J. W.; Bernardoni, M.; Dumka, D. C.; Fanning, D. M.; Kuball, M. Low thermal resistance GaN-on-diamond transistors characterized by three-dimensional Raman thermography mapping. Appl. Phys. Lett. 2014, 104, No. 083513.

(11) Hirama, K.; Taniyasu, Y.; Kasu, M. AlGaN/GaN high-electron mobility transistors with low thermal resistance grown on single-crystal diamond (111) substrates by metalorganic vapor-phase epitaxy. Appl. Phys. Lett. 2011, 98, No.162112.

(12) Gerrer, T.; Cimalla, V.; Waltereit, P.; Müller, S.; Benkhelifa, F.; Maier, T.; Czap, H.; Ambacher, O.; Quay, R. Transfer of AlGaN/GaN RF-devices onto diamond substrates via van der Waals bonding. International Journal of Microwave and Wireless Technologies, 2018, 10, 666 - 673.

(13) Wu, Q.; Xu, Y.; Zhou, J.; Kong, Y.; Chen, T.; Wang, Y.; Lin, F.; Fu, Y.; Jia, Y.; Zhao, X.; Yan, B.; $\mathrm{Xu}, \mathrm{R}$. Performance Comparison of GaN HEMTs on Diamond and SiC Substrates Based on Surface Potential Model. ECS J. Solid State Sci. Technol. 2017, 6, Q171 - Q178.

(14) Saura, A.; Ji, H.; Hilton, K. P.; Wallis, D. J.; Uren, M. J.; Martin, T.; Kuball, M. Thermal boundary 
resistance between $\mathrm{GaN}$ and substrate in $\mathrm{AlGaN} / \mathrm{GaN}$ electronic devices. IEEE Trans. Electron Devices 2007, 54, $3152-3158$.

(15) Du, M.; Guo, Q.; Ouyang, Z.; Wei, K.; Hurley, W. G. Effects of solder layer crack on the thermal reliability of insulated Gate Bipolar Transistors. Case Studied in Thermal Engineering 2019, 14, No. 100492.

(16) Jourdain, A.; Stoukatch, S.; De Moor, P.; and Ruythooren, W. Simultaneous Cu-Cu and Compliant Dielectric Bonding for 3D Stacking of ICs. Proc. IITC, 2007, p. 207.

(17) Okuno, Y.; Aoki, M.; Tsuchiya, T.; and Uomi, K.; Fabrication of (001) Inp-based 1.55-m wavelength lasers on a (110) GaAs substrate by direct bonding (A prospect for free-orientation integration) Appl. Phys. Lett. 1995, 67, NO. 810.

(18) Tan, C. M.; Yu, W.; and Wei, J. Comparison of medium-vacuum and plasma-activated lowtemperature wafer bonding. Appl. Phys. Lett. 2006, 88, No. 114102.

(19) Liang, J.; Miyazaki, T.; Morimoto, M.; Nishida, S.; Watanabe, N.; Shigekawa, N. Electrical properties of $\mathrm{p}-\mathrm{Si} / \mathrm{n}-\mathrm{GaAs}$ Heterojunctions by Using Surface-Activated Bonding. Appl. Phys. Express 2013, 6, No. 021801.

(20) Higurashi, E.; Okumura, K.; Nakasuji, K.; and Suga, T. Surface activated bonding of GaAs and $\mathrm{SiC}$ wafers at room temperature for improved heat dissipation in high-power semiconductor lasers. Jpn. J. Appl. Phys. 2015, 54, No. 030207.

(21) Liang, J.; Masuya, S.; Kasu, M.; Shigekawa, N. Realization of direct bonding of single crystal 
diamond and Si substrates. Appl. Phys. Lett. 2017, 110, No.111603.

(22) Sakata, M.; Oyake, T.; Maire, J.; Nomura, M.; Higurashi, E.; and Shiomi, J. Thermal conductance of silicon interface directly bonded by room-temperature surface activation. Appl. Phys. Lett. 2015, 106, No. 081603.

(23) Liang, J.; Yamajo, S.; Kuball, M.; Shigekawa, N. Room-temperature direct bonding of diamond and Al. Scripta Mater. 2019, 159, 58 - 61.

(24) Kanda, S.; Shimizu, Y.; Ohno, Y.; Shirasaki, K.; Nagai, Y.; Kasu, M.; Shigekawa, N.; Liang, J. Fabrication of diamond/Cu direct bonding interface for power device applications. Jpn. J. Appl. Phys. 2019, 59, No. SBBB03.

(25) Yamashita, Y.; Honda, K.; Yagi, T.; Jia, J.; Taketoshi, N.; Shigesato, Y. Thermal conductivity of hetero-epitaxial $\mathrm{ZnO}$ thin films on c- and r-plane sapphire substrates: Thickness and grain size effect. J. Appl. Phys. 2019, 125, No. 035101.

(26) Taketoshi, N.; Baba, T.; Schaub, E.; Ono, A. Homodyne detection technique using spontaneously generated reference signal in picosecond thermoreflectance measurements. Rev. Sci. Instrum. 2003, 74, No. 5226 .

(27) T Yagi. Kobayashi, K. In Proceedings of the 35th Japan Symposium Thermophysical Properties. 2014 Japan Society of Thermophysical Properties Symposium (JSTP); 2014, pp 16 - 20 (in Japanese). (28) Taketoshi, N.; Baba, T.; Ono, A. Electrical delay technique in the picosecond thermoreflectance method for thermophysical property measurements of thin films. Rev. Sci, Instrum. 2005, 76, No. 
094903.

(29) Chiristian, M.; Ludger, W.; Thermal boundary conductance of transition metals on diamond. Emerging Materials Research, 2012, 1, 89-98.

(30) Wang, H. Xu, Y. Shimono, M. Tanaka, Y. Yamazaki, M. Computation of Interfacial Thermal Resistance by Phonon Diffuse Mismatch Model. Materials Transactions, 2007, 48, 2349 - 2352.

(31) Liang, J.; Miyazaki, T.; Morimoto, M.; Nishida, S.; Shigekawa, N. Electrical properties of Si/Si interfaces by using surface-activated bonding. J. Appl. Phys. 2013, 114, No. 183703.

(32) Liang, J.; Chai, L.; Nishida, S.; Morimoto, M.; and Shigekawa, N. Investigation on the interface resistance of $\mathrm{Si} / \mathrm{GaAs}$ heterojunctions fabricated by surface-activated bonding. Jpn. J. Appl. Phys. 2015, 54, No. 030211 .

(33) Liang, J.; Nishida, S.; Arai, M.; Shigekawa, N. Effects of thermal annealing process on the electrical properties of $\mathrm{p}^{+}-\mathrm{Si} / \mathrm{n}-\mathrm{SiC}$ heterojunctions. Appl. Phys. Lett. 2014, 104, No. 161604.

(34) Ohno, Y.; Yoshida, H.; Takeda, S.; Liang, J.; Shigekawa, N. Intrinsic microstructure of Si/GaAs heterointerfaces fabricated by surface-activated bonding at room temperature. Jpn. J. Appl. Phys. 2018, 57, No. 02BA01.

(35) Kim, T.; Howlader, H. M. M.; Itoh, R. T.; Suga, T. Room temperature $\mathrm{Cu}-\mathrm{Cu}$ direct bonding using surface activated bonding method. J. Vac. Sci. \& Technol. A 2003, 21, No. 449.

(36) Lee, S.; Hsu, H.; Tuan, W. Oxidation Behavior of Copper at a Temperature below $300{ }^{\circ} \mathrm{C}$ and the Methodology for Passivation. Mat. Res. 2016, 19, 51 - 56. 
(37) Howlader, M. M. R.; Zhang, F. Void-free strong bonding of surface activated silicon wafers from room temperature to annealing at $600^{\circ} \mathrm{C}$. Thin Solid Films, 2010, 519, $804-808$.

(38) Yamajo, S.; Yoon, S.; Liang, J.; Sodabanlu, H.; Watanabe, K.; Sugiyama, M.; Yasui, A.; Ikenaga, E.; Shigekawa, N. Hard X-ray photoelectron spectroscopy investigation of annealing effects on buried oxide in GaAs/Si junctions by surface-activated bonding. Appl. Surf. Sci. 2019, 473, 627 - 632 .

(39) Liang, J.; Masuya, S.; Kim, S.; Oishi, T.; Kasu, M.; Shigekawa, N. Stability of diamond/Si bonding interface during device fabrication process. Appl. Phys. Express 2019, 12, No. 016501.

(40) Guillemet, T.; Geffroy, P. M.; Heintz, J. M.; Chandra, N.; Lu, Y. F.; Silvain, J. F. An innovative process to fabricate copper/diamond composite films for thermal management applications. Composites Part a: Applied Science and Manufacturing 2012, 43, 1746 - 1753.

(41) Liang, J.; Zhou, Y.; Masuya, S.; Gucmann, F.; Singh, M.; Pomeroy, J.; Kim, S.; Kuball, M.; Kasu, M.; Shigekawa, N. Annealing effect of surface-activated bonded diamond/Si interface. Diam. Relat. Mater. 2019, 93, $187-192$.

(42) Suzuki, T. X-Ray Study on the Binding Properties of $\mathrm{Cu}_{2} \mathrm{O}$ and $\mathrm{Ag}_{2} \mathrm{O}$ Crystals. J. Phys. Soc. Jpn. 1960, $15,2018-2024$.

(43) Chu, K.; Wang, J.; Liu, Y. P.; Geng, Z. R. Graphene defect engineering for optimizing the interface and mechanical properties of graphene/copper composites. Carbon, 2018, 140, 112-123.

(44) Chu, K.; Wang, J.; Liu, Y. P.; Li, Y. B.; Geng, Z. R.; Zhang, H. Creating defects on graphene basalplane toward interface optimization of graphene/CuCr composites. Carbon, 2019, 143, 85-96. 
Table I. Parameters used in the lock-in thermal reflectance signal simulation.

\begin{tabular}{lccc}
\hline \hline Layer & Mo & $\mathrm{Cu}$ & Diamond \\
\hline Thickness $(\mathrm{nm})$ & 99 & 100 & bulk \\
Thermal conductivity $(\mathrm{W} / \mathrm{m} \cdot \mathrm{K})$ & 5.3 & 377 & 1000 \\
Density $\left(\mathrm{kg} / \mathrm{m}^{3}\right)$ & 10220 & 8940 & 3510 \\
Specific heat capacity $(\mathrm{J} / \mathrm{kg} \cdot \mathrm{K})$ & 248 & 384 & 548 \\
Volumetric Heat Capacity $\left(\mathrm{J} / \mathrm{m}^{3} \cdot \mathrm{K}\right)$ & $2.53 \times 10^{6}$ & $3.43 \times 10^{6}$ & $1.92 \times 10^{6}$ \\
\hline
\end{tabular}

Table II. TBR with uncertainties for $\mathrm{Mo} / \mathrm{Cu}$ and $\mathrm{Cu} /$ diamond interfaces.

\begin{tabular}{c|c|c}
\hline \hline & TBR of Mo/Cu & TBR of Cu/diamond \\
\hline SAB & $1.4 \pm 0.4 \times 10^{-8} \mathrm{~m}^{2} \cdot \mathrm{K} / \mathrm{W}$ & $1.7 \pm 0.2 \times 10^{-8} \mathrm{~m}^{2} \cdot \mathrm{K} / \mathrm{W}$ \\
\hline EBD & $1.4 \pm 0.6 \times 10^{-8} \mathrm{~m}^{2} \cdot \mathrm{K} / \mathrm{W}$ & $1.7 \pm 0.3 \times 10^{-8} \mathrm{~m}^{2} \cdot \mathrm{K} / \mathrm{W}$ \\
\hline
\end{tabular}




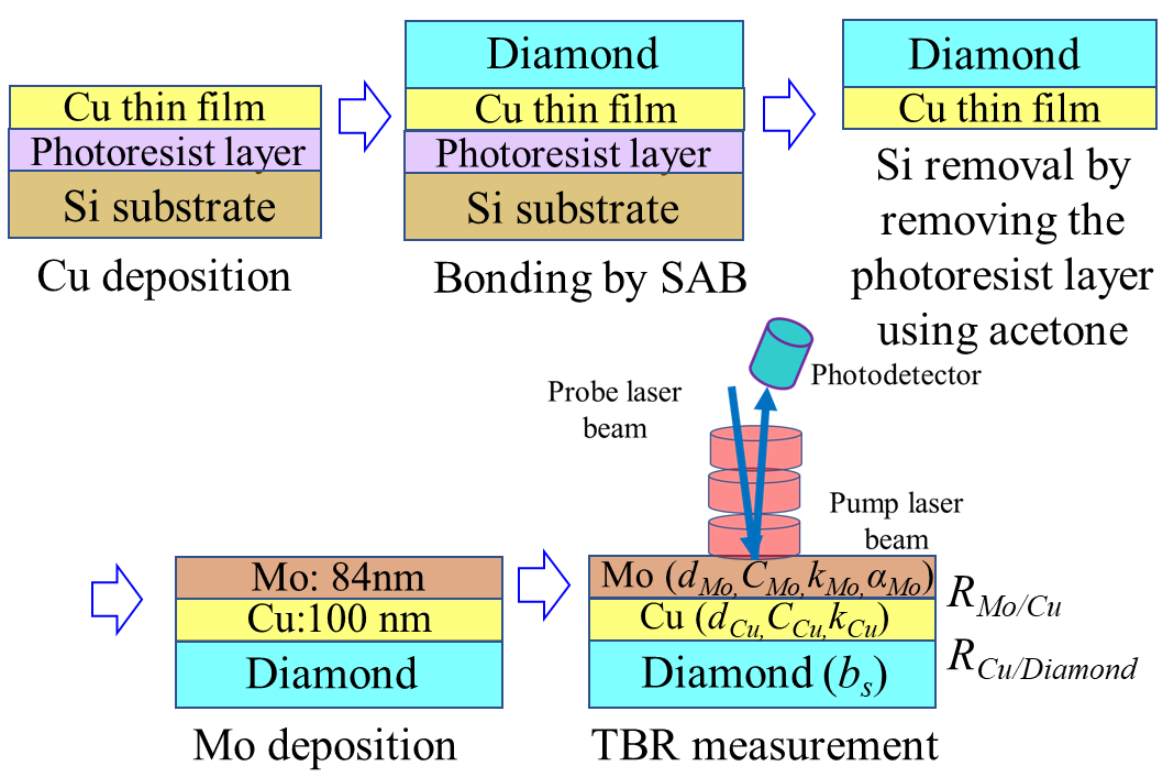

Figure 1. Schematic diagram of the fabrication of thin- $\mathrm{Cu} /$ diamond bonded structures and measurement of the TBR. 

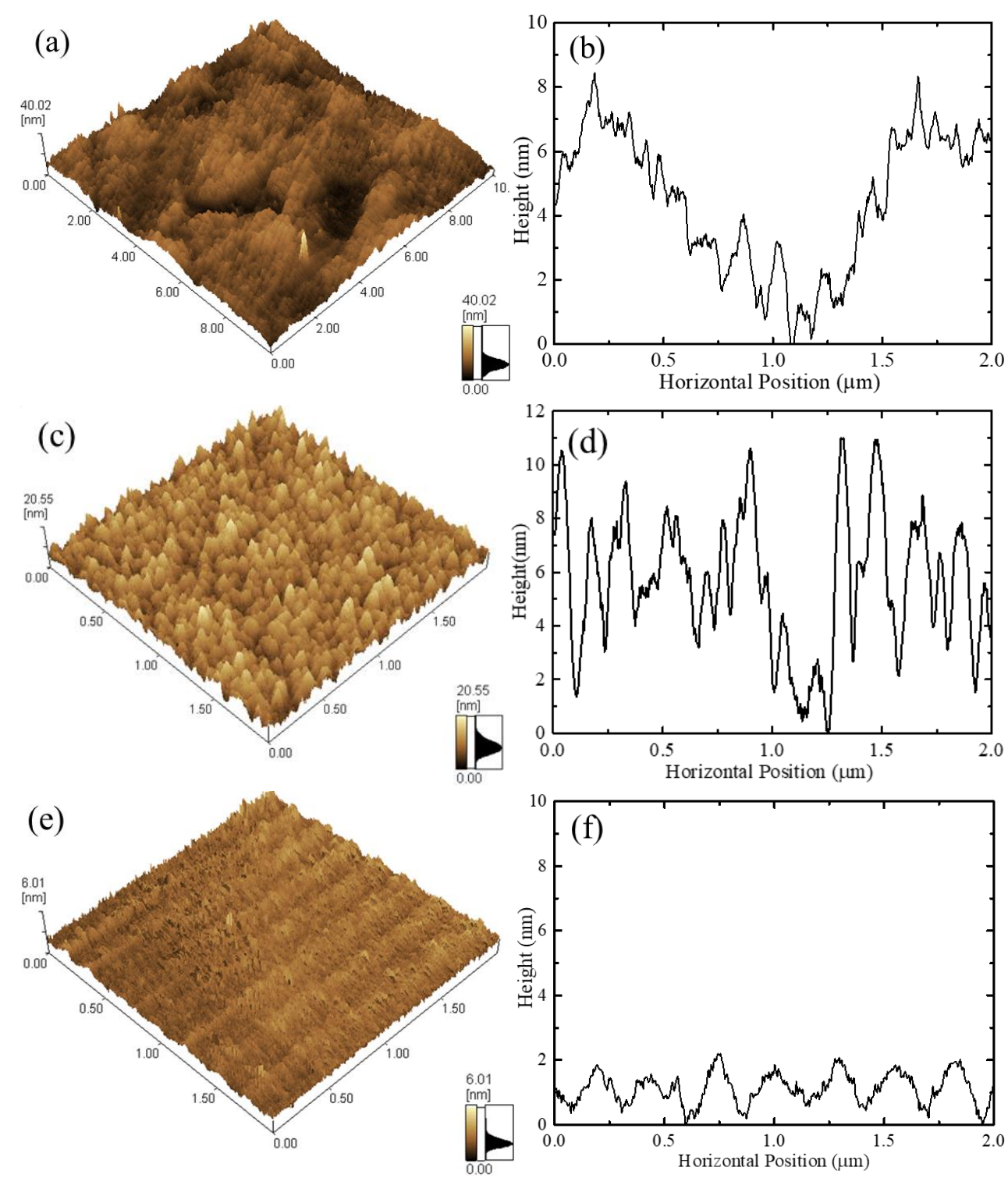

Figure 2. AFM images and corresponding cross-sectional profiles of the $\mathrm{Cu}$ plate (a) and (b), the deposited $\mathrm{Cu}$ thin film (c) and (d), and the diamond substrate (e) and (f) surfaces. 

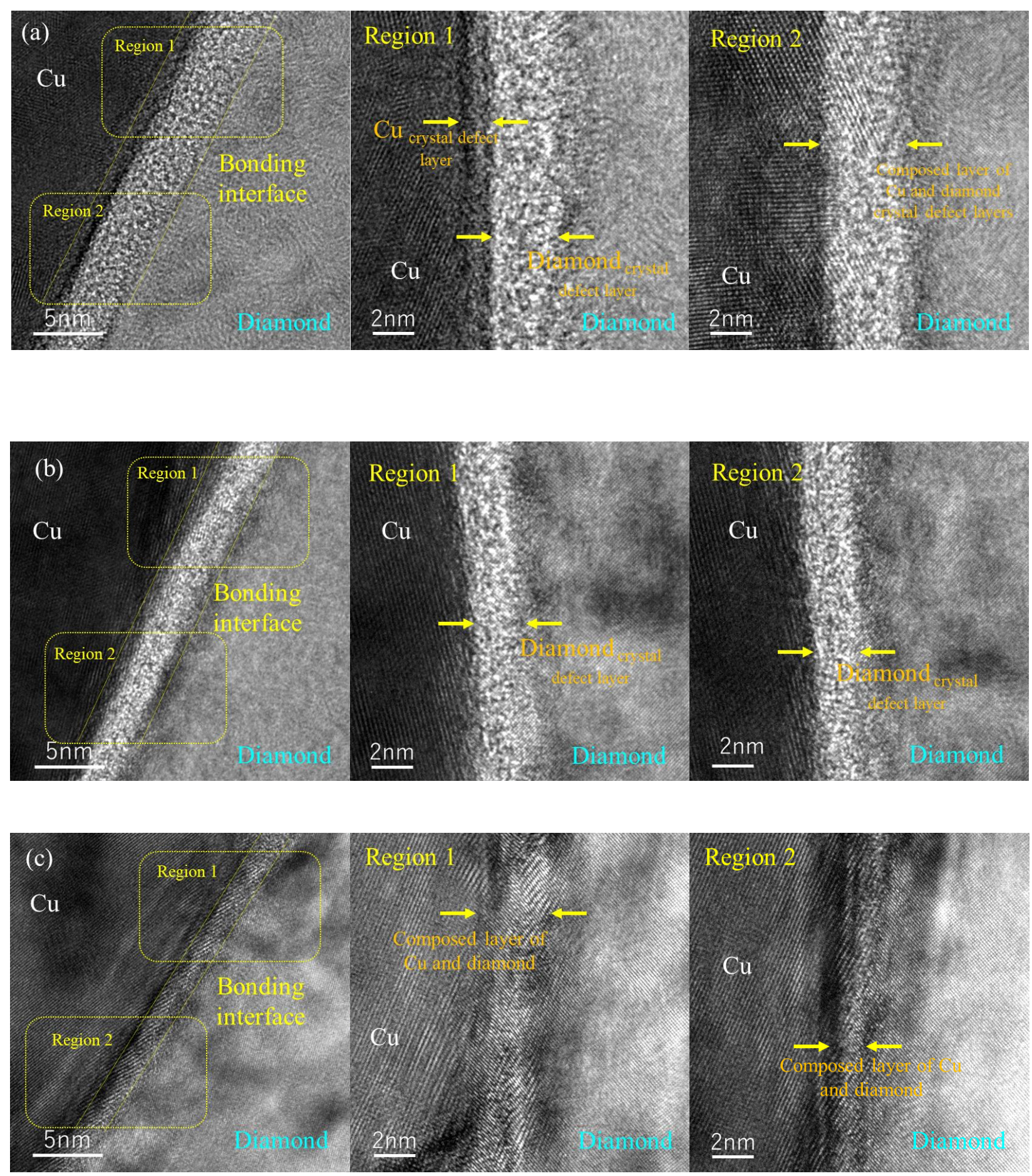

Figure 3. Cross-sectional STEM images of the as-bonded $\mathrm{Cu}$ /diamond interface (a) and the interfaces annealed at 500 (b) and $700{ }^{\circ} \mathrm{C}$ (c). 
(a)
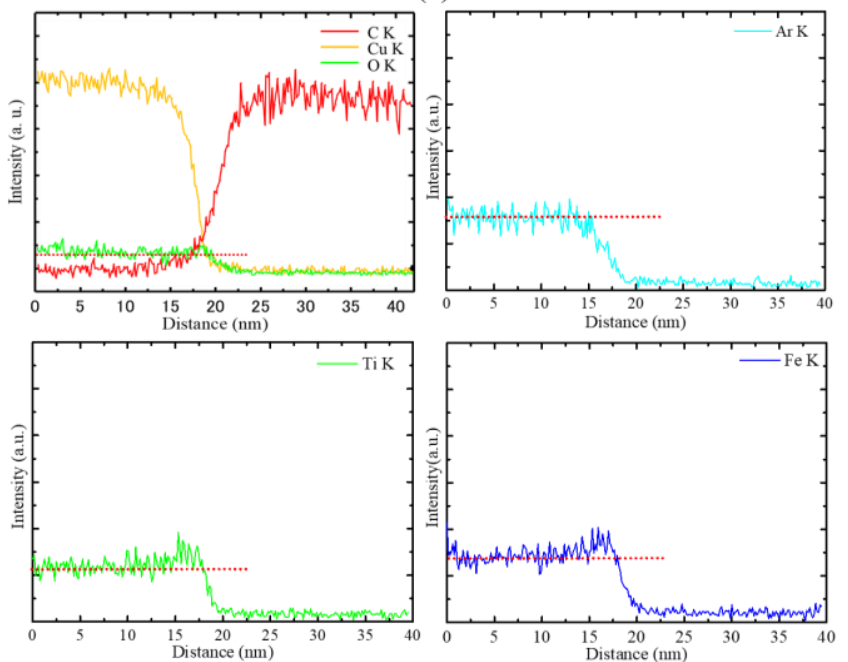

(b)
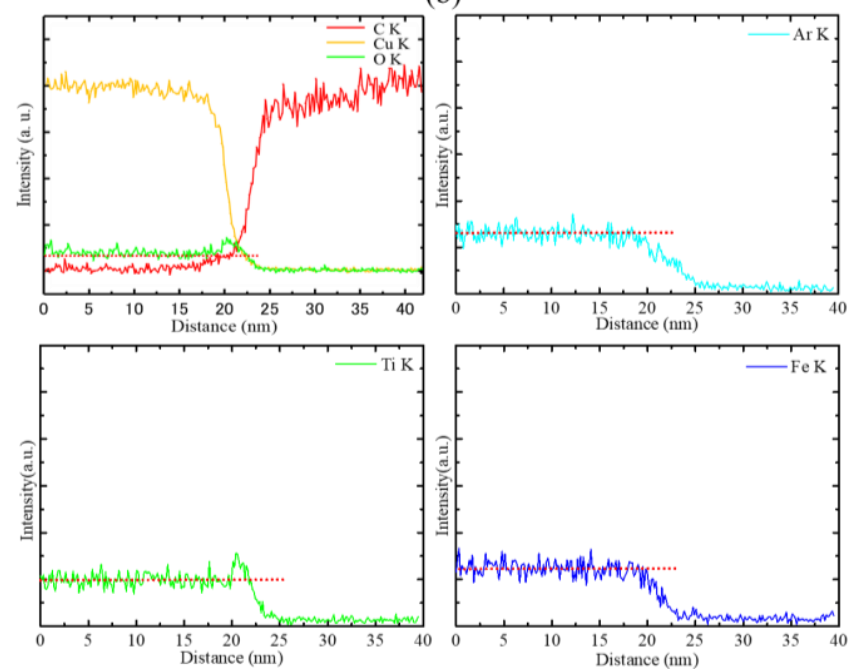

(c)
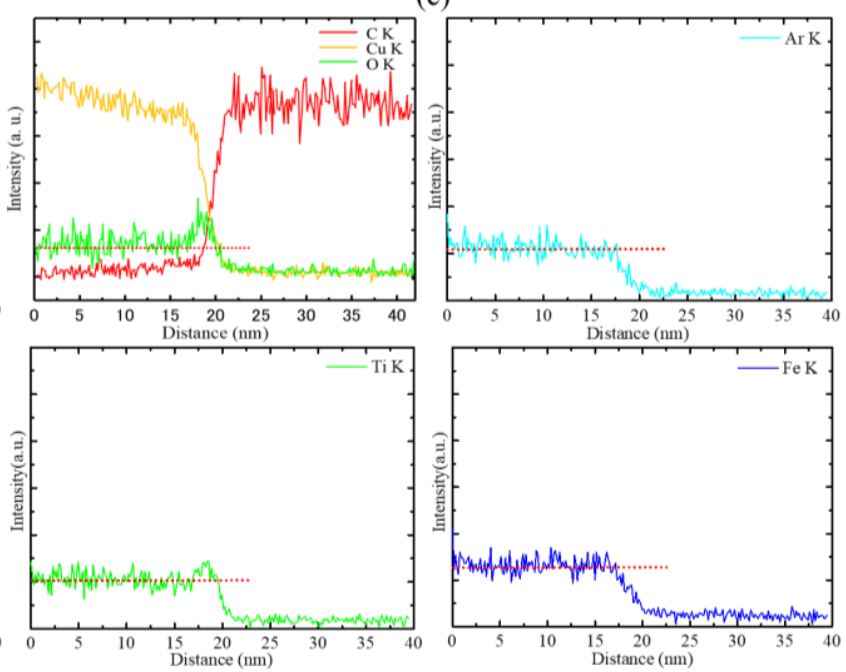

Figure 4. $\mathrm{X}$-ray intensity profiles of $\mathrm{C}, \mathrm{Cu}, \mathrm{O}, \mathrm{Ar}, \mathrm{Ti}$, and $\mathrm{Fe}$ in the as-bonded $\mathrm{Cu}$ /diamond interface

(a) and the interfaces annealed at 500 (b) and $700{ }^{\circ} \mathrm{C}$ (c). The red dotted line shows the average intensity of the background noise. 

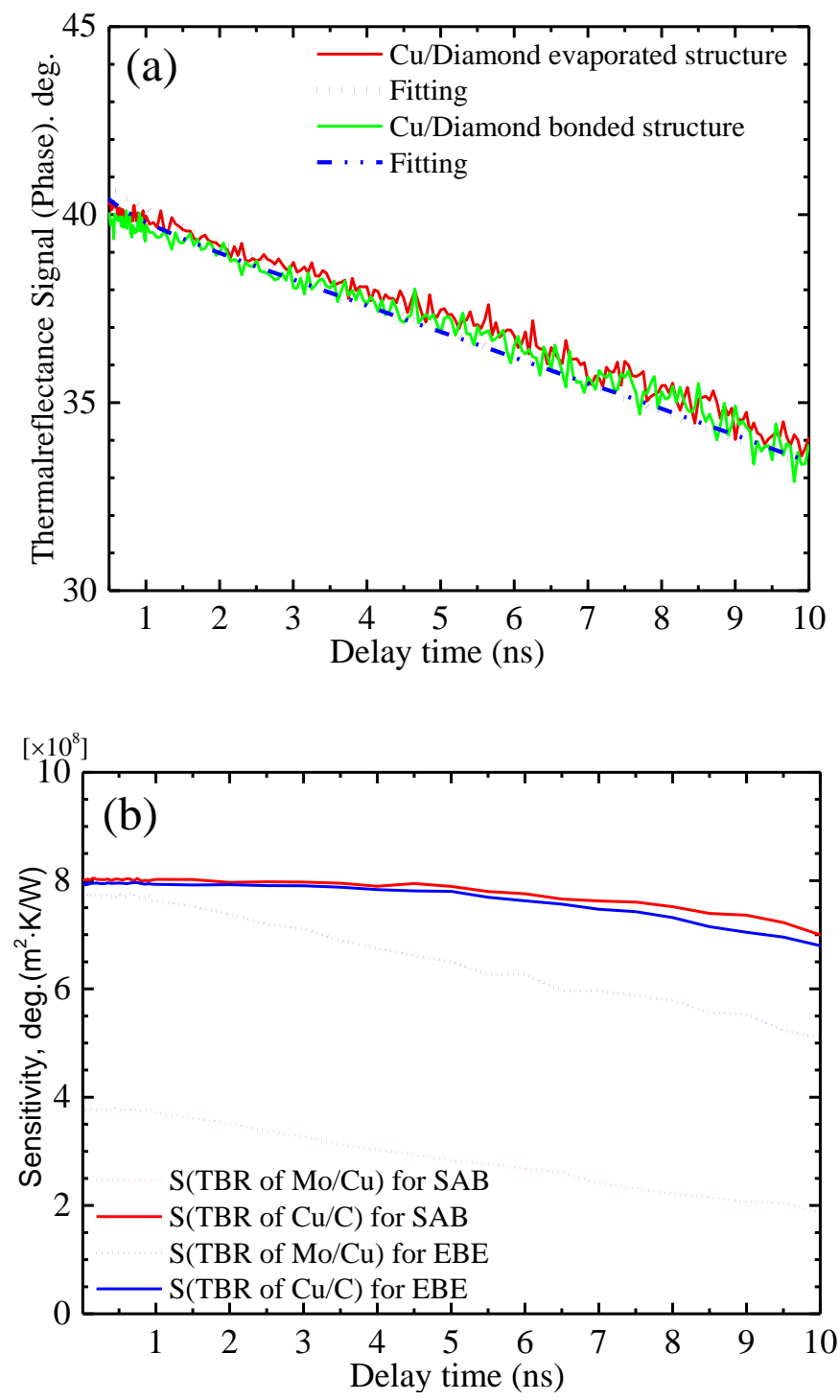

Figure 5. Thermal reflectance signals (solid line) and fitting results (solid circle) for delay times ranging from 0.5 to $10 \mathrm{~ns}$ for the as-bonded $\mathrm{Cu}$ /diamond structure and the $\mathrm{Cu} /$ diamond evaporated structure as a reference (a) and sensitivity as a function of delay times for TBRs of $\mathrm{Mo} / \mathrm{Cu}$ interfaces and $\mathrm{Cu}$ /diamond interfaces (b). 